\title{
Magnetic Fluid Hyperthermia of Rodent Tumors Using Manganese Perovskite Nanoparticles
}

\author{
Larissa Bubnovskaya, ${ }^{1}$ Anatolij Belous, ${ }^{2}$ Sergej Solopan, ${ }^{2}$ Antonina Kovelskaya, \\ Lyudmila Bovkun, ${ }^{1}$ Alexander Podoltsev, ${ }^{3}$ Igor Kondtratenko, ${ }^{3}$ and Sergej Osinsky ${ }^{1}$ \\ ${ }^{1}$ R.E. Kavetsky Institute of Experimental Pathology, Oncology and Radiobiology, National Academy of Sciences of Ukraine, \\ Vasilkovskaya Street 45, Kiev 03022, Ukraine \\ ${ }^{2}$ V.I. Vernadsky Institute of General and Inorganic Chemistry, National Academy of Sciences of Ukraine, Prospekt Palladina 32/34, \\ Kiev 03142, Ukraine \\ ${ }^{3}$ Institute of Electrodynamic, National Academy of Sciences of Ukraine, Prospekt Pobedy 56, Kiev 03057, Ukraine
}

Correspondence should be addressed to Sergej Osinsky; osinskysp12@ukr.net

Received 30 May 2014; Accepted 18 July 2014; Published 14 August 2014

Academic Editor: Fabien Grasset

Copyright ( 2014 Larissa Bubnovskaya et al. This is an open access article distributed under the Creative Commons Attribution License, which permits unrestricted use, distribution, and reproduction in any medium, provided the original work is properly cited.

\begin{abstract}
Purpose. To test the antitumor activity of magnetic fluid (MF) on the basis of substituted lanthanum-strontium manganite nanoparticles combined with alternating magnetic field (AMF) in experiments with transplanted tumors. Materials and Methods. MF with a size of nanoparticles of 30-40 nm in aqueous agarose solution was investigated. The ability of MF to heat tumor under $\operatorname{AMF}(300 \mathrm{kHz}, 7.7 \mathrm{kA} / \mathrm{m})$ was tested in vivo with rodent tumors (Guerin carcinoma, Walker-256 carcinosarcoma, and Lewis lung carcinoma (3LL)). Results. Single administration of MF into the tumor at a dose of $150 \mathrm{mg} / \mathrm{kg}$ (rats) or $200 \mathrm{mg} / \mathrm{kg}$ (mice) followed by AMF within 20-30 min (treatment was repeated 3-4-fold) has resulted in the complete regression of tumor in the 35\% of rats and $57 \%$ of mice. Administration of MF alone or action of AMF alone has not resulted in tumor growth inhibition. The chemomodifying effect of nanohyperthermia was determined, in particular for cisplatinum: thermal enhancement ratio was 2.0. It was also observed that nanohyperthermia has resulted in the absence of 3LL metastases in 43\% of mice. Conclusions. MF on the basis of lanthanumstrontium manganite may be considered as an effective inductor of tumor local hyperthermia.
\end{abstract}

\section{Introduction}

The hyperthermia (HT) of human malignant tumor is used in the combined antitumor therapy and demonstrates significant modifying effect that results in the improvement of patients' survival [1-3]. At the same time technical problems of microwave HT, that is, a main method for tumor heating, do not allow receiving the maximal homogenous heating of tumor and cause the definite side effects.

One of the approaches to resolve this problem is a creation of magnetic fluids (MF) on the basis of ferromagnetic nanoparticles which are able to heat the tumor tissue under external alternating magnetic field (AMF), that was shown in the pioneer work of Jordan et al. [4]. The use of nanosized magnetic particles, which are able to generate heat under AMF, offers much extensive scope for the use of HT in the therapy of malignant tumors [5-7]. The effective application of magnetic nanoparticles was shown in the combination with AMF in the experiment with transplanted tumors both in the regime of thermal ablation and thermochemotherapy $[8,9]$. The nanoparticles of ferromagnetic materials have to meet various requirements; in particular, they must be slightly agglomerated, small sized, single-domained, easily excretable from the body, able to demonstrate high values of the SLP (specific loss power), and able to exhibit superparamagnetic properties that would not lead to the interaction of particles after removing the magnetic field $[5,6,10]$.

The studies of MF on the basis of magnetite nanoparticles, that is, $\mathrm{Fe}_{3} \mathrm{O}_{4}$, that has the high level of biocompatibility, have received significant distribution since the first publication of Jordan et al. [4]. Among many of publications we would 
like here to emphasize the some most important. It was demonstrated that thermotherapy using magnetic iron-oxide nanoparticles in combination with radiotherapy on patients with recurrent glioblastoma resulted in the longer overall survival compared to conventional therapies [11]. Johannsen et al. [12] have presented data based on the interstitial heating of prostate cancer using direct intratumoral injection of magnetic nanoparticles followed by an AMF in two separate clinical studies, namely, employing magnetic nanoparticle thermotherapy alone and in combination with permanent seed brachytherapy and suggested that thermoablation can be applied safely as a monotherapy as well as nanothermotherapy in combination with irradiation in patients with localised prostate cancer. It was shown that hyperthermia using magnetic heating of iron oxide nanoparticles combined with AMF caused necrosis in mouse xenograft model of human head and neck cancer [13]. Hayashi et al. [14] have applied alternating magnetic field in the day after intravenous injection of superparamagnetic nanoparticles modified with folic acid and polyethylene glycol into mice bearing xenograft tumor derived from a multiple myeloma cell line that resulted in the significant inhibition of tumor growth.

At the same time the high Curie point (phase transition point) of magnetite is a cause of overheating of normal tissue surrounding the tumor $[17,18]$. Among the promising approaches to enhance tumor hyperthermia efficacy by MF, there is the use of lanthanum-strontium manganite perovskites. It is known that their magnetic properties can be modified, in particular by the change of coating and size of nanoparticles [17-20]. The samples of such nanocomposites were received by some authors, and their ability to be heated in the AMF in vitro was shown $[15,17-20]$. In the early publication, it was demonstrated that the temperature of manganite powder can be elevated by $\mathrm{AMF}$ to $45^{\circ} \mathrm{C}$ in 10-15 min after the onset of AMF action followed by stabilization on this level [19]. The influence of stoichiometry, size, and coating of $\mathrm{La}_{1-x} \mathrm{Sr}_{x} \mathrm{MnO}_{3}$ nanoparticles were studied and shown that they are characterized by "a tunable Curie point within the broad range temperature used in hyperthermia treatments $40-70^{\circ} \mathrm{C}^{\prime}[20]$. Pollert et al. [15] have presented results of the extended study of core-shell $\mathrm{La}_{1-x} \mathrm{Sr}_{x} \mathrm{MnO}_{3}$ nanoparticles. It was shown, in particularly, that the temperature of stable water suspension of manganite was increased to $64^{\circ} \mathrm{C}$ under action of AMF within $30 \mathrm{~min}$. It was also observed that extracellular heating of rat MSCs cells due to application of magnetite in combination with AMF has resulted in the decrease of cellular viability by $80 \%$.

At the same time the analysis of the obtained results has indicated the necessity to optimize the synthesis and to enhance their magnetic properties [21]. The questions are now under discussion concerning the coating of nanoparticles, influence of the agglomeration, and the size of nanoparticles on the efficacy of heating, distribution of nanoparticles in the tumor, and the manifestation of magnetic properties of nanoparticles in the specific tumor microenvironment. It is relevant to note that publications in the available scientific literature contained the data about the heating of biological tissues by the magnetic fluid on the basis of lanthanum

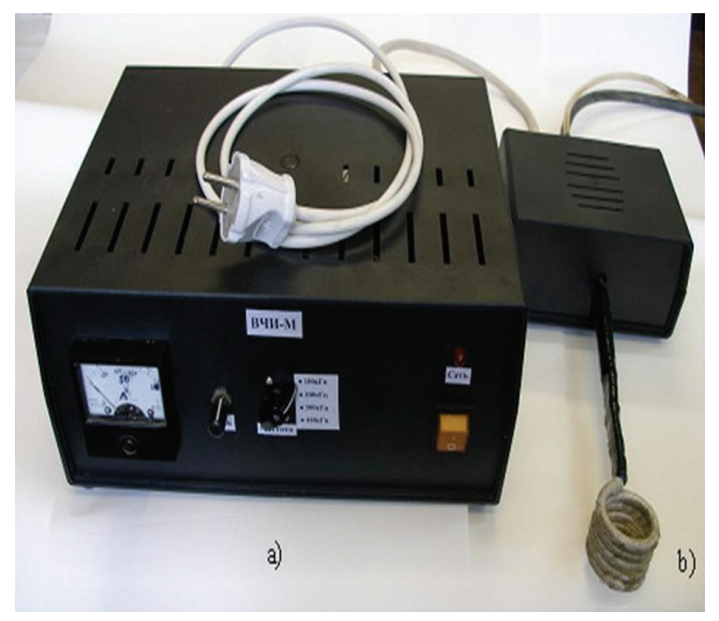

FIGURE 1: Experimental setup consists of a high frequency generator (a) and coil (b).

strontium manganite, in particular of malignant tumor in the system in vivo, are absent.

\section{Materials and Methods}

2.1. Synthesis of $\mathrm{La}_{1-x} \mathrm{Sr}_{x} \mathrm{MnO}_{3}$ Nanoparticles by Sol-Gel Method and Magnetic Fluid Preparation. Solid solution of $\mathrm{La}_{1-x} \mathrm{Sr}_{x} \mathrm{MnO}_{3}\left(x_{\text {Sr }}=0.225-0.3\right)$ has been synthesized by sol-gel method, the use of which ensures high homogeneity of resulting products [22, 23]. Water-soluble metal salts $\mathrm{La}\left(\mathrm{NO}_{3}\right)_{3}, \mathrm{Sr}\left(\mathrm{NO}_{3}\right)_{2}$, and $\mathrm{Mn}\left(\mathrm{NO}_{3}\right)_{2}$ were used as starting reagents. Calculated amounts of reagents were dissolved in distilled water. Citric acid and ethylene glycol were added as gelling additives. Initial heat treatment of the mixture at $80^{\circ} \mathrm{C}$ resulted in polyesterification with the formation of polymeric gel. The prepared powders were further heat terated in air at $400-800^{\circ} \mathrm{C}$ in alumina crucibles for $2-4 \mathrm{~h}$.

Optimal concentration of nanoparticles $(50 \mathrm{mg} / \mathrm{mL})$ in organic-matrix solutions at which the fluid remains stable and cannot separate into layers has been determined.

2.2. Alternating Magnetic Field (AMF). A high frequency generator produced by Institute of Electrodynamics (NASU of Ukraine) was used to induce an alternating current of $70 \mathrm{~A}$ at a frequency of $100-440 \mathrm{kHz}$, maximum magnetic field strength above $7.7 \mathrm{kA} / \mathrm{m}$ (Figure 1). The current passes through a custom-made five-turn water-cooled coil of $30 \mathrm{~mm}$ in internal diameter and $30 \mathrm{~mm}$ in height to generate a magnetic field inside the coil. Technical characteristics of used generator were presented earlier [24].

2.3. In Vitro Study. The ability of MF to be heated in AMF was evaluated by the following matter: MF was placed into plastic tube at a volume of $1.5 \mathrm{~mL}$ that was located then in the 


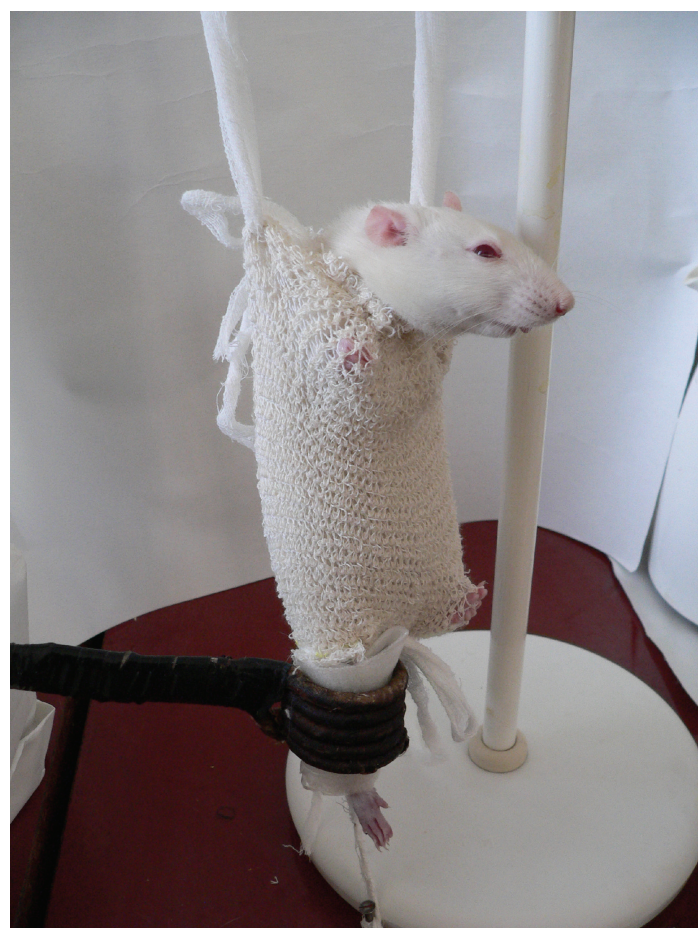

Figure 2: Rat is in the net-hammock and the femur is located in the coil of magnetic field generator.

coil of AMF generator in such way that the tube was setting up in the center of field configuration.

2.4. Animal and Tumor Models. All studies were conducted with strain IEPOR bread rats (150-250 g of b.w.) with transplanted tumors: Guerin carcinoma, carcinosarcoma Walker256, and C57Bl/6 mice (20-25 g of b.w.) bearing Lewis lung carcinoma. Tumors were transplanted intramuscularly into the femur. In separate experiments, Guerin carcinoma was transplanted into the femur of both legs of the same rat. The principle and method of transplantation were conventional. Animals were kept in Makrolon cages bedded with dust-free wood granulate and had free access to a standard diet and tap water. All experiments had been approved by the regional animal ethics committee.

It was early determined $[24,25]$ that the maximal tolerable dose of MF of lanthanum-strontium manganite by intraperitoneal administration is $300 \mathrm{mg} / \mathrm{kg}$ of b.w. The administration of MF at such dose into the tumor was safe for animals without physical injuries or weight loss and has not resulted in any side effects. To evaluate the thermal effect of MF in vivo under external AMF $(300 \mathrm{kHz}, 7.7 \mathrm{kA} / \mathrm{m})$ the special method for the heating was created; namely, MF was administered into the muscle or tumor followed by placing the animal into the special net-hammock (Figure 2).

When tumor volume has reached $1.5-2.0 \mathrm{~cm}^{3}$ (Guerin carcinoma, Walker-256 carcinosarcoma) or $150-200 \mathrm{~mm}^{3}$ (Lewis lung carcinoma), animals were enrolled into the study. Animals were anaesthetized with "Calipsovet plus" i.m. at a dose of $0.1 \mathrm{~mL} / 100 \mathrm{~g}$ of b.w. (rat) or $0.01 \mathrm{~mL} / 20 \mathrm{~g}$ of b.w. (mouse) before the onset of experiment. MF was administered into the muscle or tumor $15-30 \mathrm{~min}$ before heating a dose of $150-200 \mathrm{mg} / \mathrm{kg}$. Cisplatin (Ebewe, Austria) was injected i.p. at a dose of 1.5 or $3.0 \mathrm{mg} / \mathrm{kg}$ of b.w. $15 \mathrm{~min}$ before the onset of hyperthermia. Each animal was placed into a net-hammock suspended to make free leg with tumor for heating. The net-hammock was fixed in the tripod so that the femur of animal was localized in the water-cooled magnetic induction coil (diameter of $30.0 \mathrm{~mm}$ ) with the maximal possible positioning in the most active point of the field. In a number of experiments, the temperature was measured both in muscle and tumor of the same tumorbearing rat. The number of animals was presented in the text and tables.

2.5. Temperature Measurement. Tumor temperature during heating was measured by means of cooper-constantan thermocouples $(0.1 \mathrm{~mm}$ diameter; IF-Kiev). The thermocouples were calibrated against a certified precision mercury-inglass thermometer (Committee of State Standards, Ukraine) before and after each experiment. The temperature of MF was measured every $5 \mathrm{~min}$ during the in vitro experiment when the generator was switched off at a small interval of time $\approx 5 \mathrm{sec}$. When the temperature was measured in muscle or tumor during the experiment, the measurements were repeated every $15 \mathrm{~min}$ to avoid tissue damage by thermocouple insertion.

2.6. Statistical Analysis. Data are presented as the mean \pm s.e.m. Differences between the experimental points were evaluated by Student's $t$-test and considered as significant for $P<0.05$.

\section{Results}

3.1. Heating of MF (Experiments In Vitro). The ability of MF based on the synthesized nanoparticles of perovskite manganite $\left(\mathrm{La}_{1-x} \mathrm{Sr}_{x} \mathrm{MnO}_{3}\right)$ and water solution of agarose to be heated under AMF was evaluated as was indicated in materials and methods. The results of experiments are presented in Figure 3. It is clearly seen that MF was heated up to $70^{\circ} \mathrm{C}$ on the 5th min under AMF followed by the stabilization of temperature up to cessation of AMF action. Presented temperature curve is optimal but the mean values of MF temperature increasing were determined as $68.5 \pm$ $1.32^{\circ} \mathrm{C}$ at the 5 th min of AMF action, $72.1 \pm 1.15^{\circ} \mathrm{C}$ at the 10th $\min , 74.1 \pm 1.5^{\circ} \mathrm{C}$ at the 15 th $\mathrm{min}$, and $74.9 \pm 0.72^{\circ} \mathrm{C}$ at the 20th min, and then the temperature remains almost the same up to $60 \mathrm{~min}$ of the heating. Initial temperature of MF was $23.0 \pm 1.25^{\circ} \mathrm{C}$. After cessation of AMF action, MF temperature has dropped rather quickly ( $\Delta \approx 50^{\circ} \mathrm{C}$ within $15 \mathrm{~min}$ ) and reached preheating value up to the 20th min (more than 40 measurements were provided).

3.2. In Vivo Heating. The ability of MF injected into the muscle or tumor to heat targeted tissue was checked up in experiments in vivo (Figure 4). It was determined that the temperature of femur muscle of nontumor-bearing rat (MF 


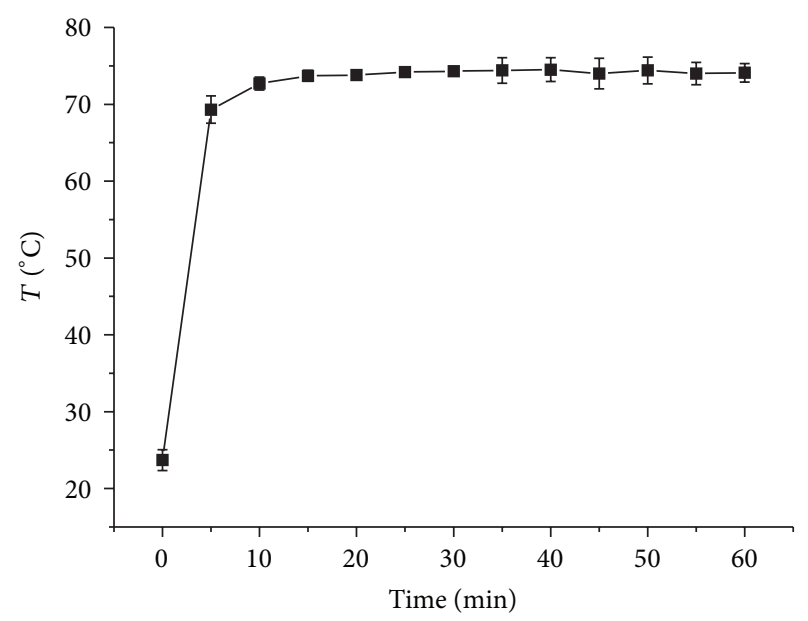

FIgURE 3: Time-dependent temperature curve of manganite MF heating induced with AMF $(300 \mathrm{kHz}, 7.7 \mathrm{kA} / \mathrm{m})$. Ordinatetemperature $\left(T,{ }^{\circ} \mathrm{C}\right)$, abscise-duration of AMF (min). Data are presented as the mean \pm s.e.m.

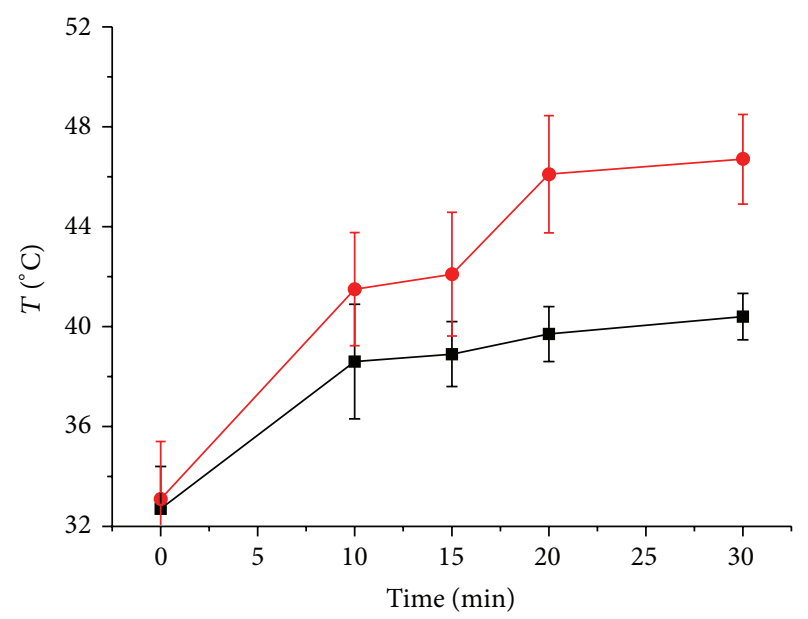

FIGURE 4: Time-dependent temperature curves of muscle as well as tumor (Guerin carcinoma) heating by MF under the AMF $(300 \mathrm{kHz}$, $7.7 \mathrm{kA} / \mathrm{m})$. - rat tumor, -rat muscle. Ordinate-temperature $(T$, $\left.{ }^{\circ} \mathrm{C}\right)$, abscise-duration of AMF (min). Data are presented as the mean is \pm s.e.m.

was administered into the muscle) was increased by $8 \pm 1.5^{\circ} \mathrm{C}$ within $30 \mathrm{~min}$ under $\operatorname{AMF}(n=8)$, and the temperature of tumor (administration into tumor, Guerin carcinoma) was increased by $13.6 \pm 1.4^{\circ} \mathrm{C}$ within $30 \mathrm{~min}$, in average $(n=24)$. Administration of $0.9 \% \mathrm{NaCl}$ solution into the muscle or Guerin carcinoma at a volume of $0.6 \mathrm{~mL}$ followed by $\mathrm{AMF}$ exposition up to $30 \mathrm{~min}$ has not resulted in any change of tissue temperature $(n=5)$ and the temperature inside the muscle or Guerin carcinoma during exposition of AMF alone was not also changed (data not presented). These results distinctly showed that MF on the basis of lanthanum-strontium manganite is able to increase the tumor temperature under AMF and can be considered as an effective inductor of tumor local hyperthermia.

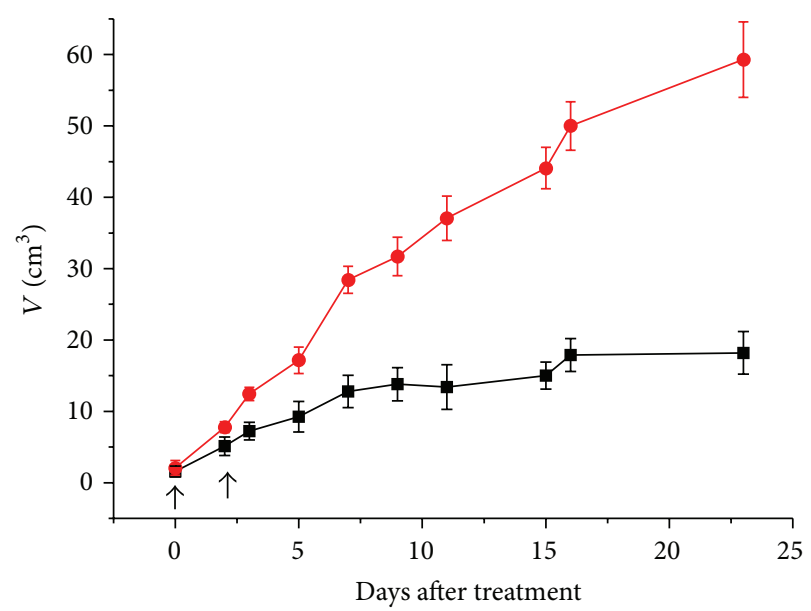

FIGURE 5: Growth of Guerin carcinoma after combined treatment MF with AMF (twice) versus growth of nontreated tumor. - - growth of nontreated tumor, - - growth of treated tumor. Ordinate-tumor volume, $\mathrm{cm}^{3}$; abscise-time of observation from the first treatment, days. Treatments were indicated with arrows. Data are presented as the mean \pm s.e.m.

\subsection{In Vivo Evaluation of Antitumor Effect of Nanohyperthermia on Rodent Tumors}

Experiments with Guerin Carcinoma. Administration of MF into the tumor at the first day of treatment only followed by AMF during 30 min (treatment was 1-2 times with 1-2 days break in different experiments) has resulted in the delay of tumor growth; that is, tumor volume remains approximately the same from the 4th day after the first treatment up to the 25th day of observation in comparison with the growth of untreated tumor $\left(15.4 \pm 1.9 \mathrm{~cm}^{3}\right.$ and $59.3 \pm 5.3 \mathrm{~cm}^{3}$, resp., $P<0.05)$ (Figure 5). Temperature in the tumor that was injected by MF followed by AMF was in average $45-46.5^{\circ} \mathrm{C}$ just at the 30th min of the heating in the moment when the generator was switched off.

There was also noted the dependence of nanohyperthermia efficacy from the number of heating sessions. Single administration of MF into the tumor followed by AMF during $30 \mathrm{~min}$ (in a series of experiments heating was repeated 3-4times with 2-3 days break) has resulted in more impressive delay of tumor growth: Figure 6 represents the data of one of the experiments (in rat number 2 bearing Guerin carcinoma, tumor was transplanted into femurs on both legs: rightwas treated, left-nontreated): tumor volume on the 13th day after the first treatment was $2.7 \mathrm{~cm}^{3}$ and in untreated rats was $47 \mathrm{~cm}^{3}$ : in average data obtained in such a kind of treatment was $2.13 \pm 0.81 \mathrm{~cm}^{3}$ and $52.9 \pm 5.0 \mathrm{~cm}^{3}$, respectively, $P<0.05$. If tumor injected by MF was treated with AMF twice, the tumor volume was increased by 4 -fold less, in average in comparison with the increase of untreated tumor volume. If tumor injected by MF was treated with AMF 4 times, the increase of tumor volume was not practically observed (approximately by 1.2-fold) and in some cases the complete regression of tumor was registered up to $35 \%$. 
TABLE 1: Results of nanohyperthermia influence on rat's solid tumors.

\begin{tabular}{lcccc}
\hline Tumor & $\begin{array}{c}\text { Index of tumor growth } \\
\text { inhibition }(\text { by } n \text {-fold })\end{array}$ & $\begin{array}{c}\text { Tumor growth delay } \\
(\text { day })\end{array}$ & $\begin{array}{c}\text { Number of rats with complete } \\
\text { tumor regression }(\%)\end{array}$ & $\begin{array}{c}\text { Number of cured rats } \\
(\%)^{*}\end{array}$ \\
\hline Guerin carcinoma & 0 & & 0 & 0 \\
Untreated control $(n=8)$ & 3.7 & $10.3 \pm 1.2$ & $35^{* *}$ & $25^{* *}$ \\
Nanohyperhermia $(n=15)$ & & & & 0 \\
Walker-256 carcinosarcoma & 0 & 0 & 15 & 0 \\
Untreated control $(n=5)$ & 3.2 & $6.0 \pm 1.0$ & 0 \\
Nanohyperthermia $(n=9)$ & & & 0 & 0 \\
\hline
\end{tabular}

${ }^{*}$ Rats with complete tumor regression and without tumor recurrence within 120 days after complete regression of tumor.

** Thermoablation effect was observed that resulted in the complete regression of tumor and absence of tumor recurrence. It has to be noted that this effect (thermoablation) is not observed after application of microwave hyperthermia ( $43-44^{\circ} \mathrm{C}$ within $60 \mathrm{~min}$; our data).

$n$ : number of rats.

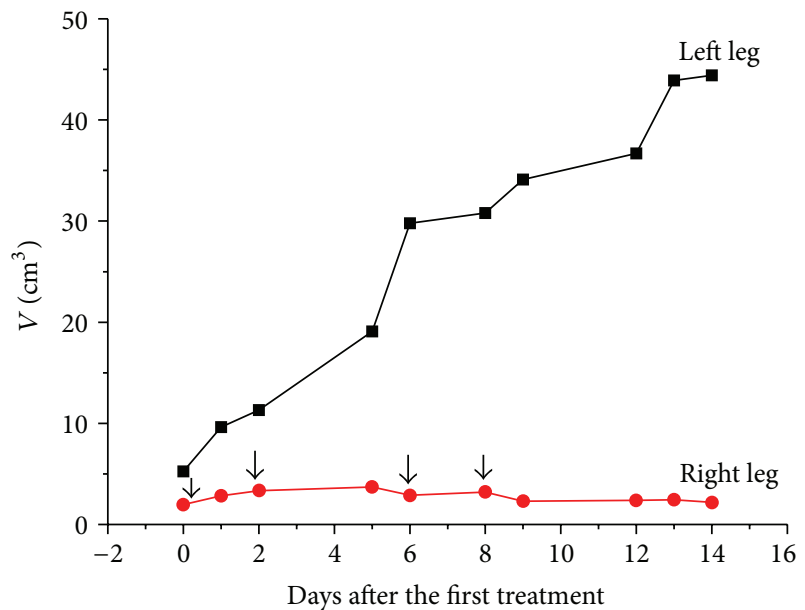

FIGURE 6: Rat number 1 (8.02.12). Growth of Guerin carcinoma after combined treatment MF with AMF versus growth of nontreated tumor: tumor was transplanted into both femurs on the same rat. - - growth of treated tumor (right leg), —-growth of nontreated tumor (left leg). Ordinate-tumor volume, $\mathrm{cm}^{3}$; abscise-time of observation from the first treatment, days. Treatments were indicated with arrows.

Obtained results are presented in Table 1 . It is very important to note that after heating sessions of AMF alone growth of the tumor was prolonged but the tumors grew something more slowly as compared with untreated tumors.

Experiments with Walker-256 Carcinosarcoma. Administration of MF into the tumor at the first day of the treatment only followed by AMF during 30 min (treatment was 2 times with 1-2 days break in different experiments) has resulted in the delay of tumor growth since the 7-8th day after the first treatment up to the 20th day of the observation in comparison with the growth of untreated tumor $\left(13.4 \pm 1.9 \mathrm{~cm}^{3}\right.$ and $30.3 \pm$ $2.6 \mathrm{~cm}^{3}$, resp., $P<0.05$ ) (Figure 7).

Temperature in tumor under influence of combined treatment with MF and AMF was reached in the average $46.4-47.0^{\circ} \mathrm{C}$ at the 30 th $\min$ of the treatment. Complete regression of tumor was registered in $15 \%$ of cases.

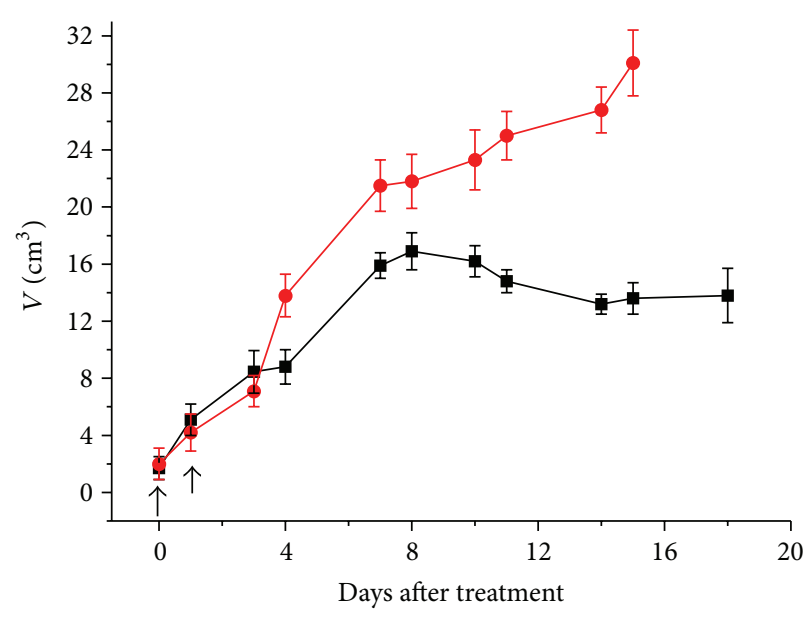

FIGURE 7: Growth of Walker-256 carcinosarcoma after combined treatment MF with AMF (twice) versus growth of nontreated tumor. - - growth of nontreated tumor, घ-growth of treated tumor. Ordinate-tumor volume, $\mathrm{cm}^{3}$; abscise-time of observation from the first treatment, days. Treatments were indicated with arrows. Data are presented as the mean \pm s.e.m.

In Vivo Evaluation of Chemomodifying Effect of Nanohyperthermia. The efficacy of nanohyperthermia combined with chemotherapy, in particular with cisplatin, was evaluated. The schedule of experiment was as follows: 1st group-nontreated tumor-bearing rats; 2 d $-\mathrm{MF}$ at a dose of $150 \mathrm{mg} / \mathrm{kg}$ was injected into the tumor, and cisplatin at a dose of $1.5 \mathrm{mg} / \mathrm{kg}$ was injected intraperitoneally ( 30 and $15 \mathrm{~min}$ before heating, resp.) supplemented with AMF within $30 \mathrm{~min}$. MF was injected once at the day of the 1st treatment whereas cisplatin was injected twice-at the day of the 1st and the 2nd treatments. Treatment was repeated three times within 2-3 days break in different experiments; the 3rd group-cisplatin at a dose of $3.0 \mathrm{mg} / \mathrm{kg}$ used alone was injected at the day of the 1st and the 2nd treatments (Figures 8 and 9). The schedule of experiments with Walker-256 carcinosarcoma was the same as with Guerin carcinoma, only with the difference that in the 2nd group treatment was applied once (Figure 10).

The equivalency of antitumor effect of cisplatin at a dose of $3.0 \mathrm{mg} / \mathrm{kg}$ used alone and those of cisplatin at a dose of $1.5 \mathrm{mg} / \mathrm{kg}$ used in combination with nanohyperthermia 


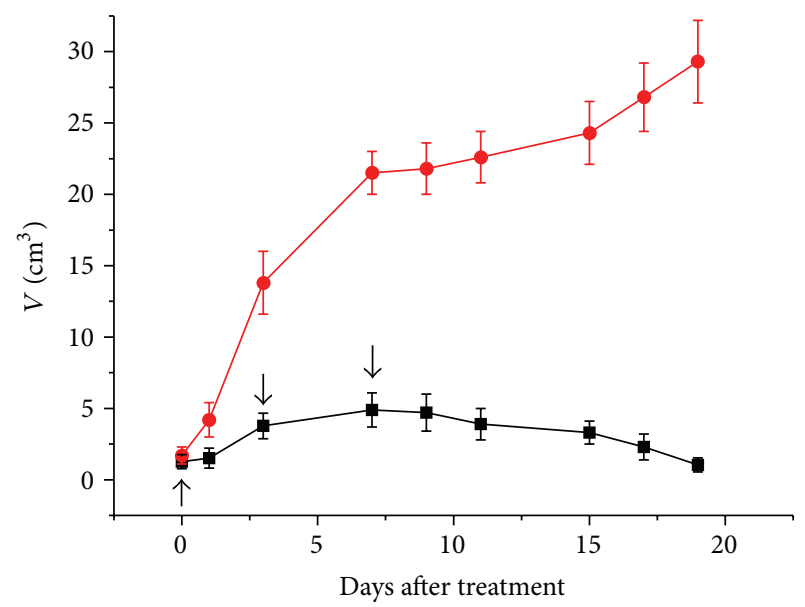

FIGURE 8: Growth of Guerin carcinoma after combined treatment by MF with AMF supplemented with cisplatinum. a-growth of treated tumor; - - growth of nontreated tumor. Treatments (nanohyperthermia) were indicated with arrows. Cisplatinum was administered twice (on the 1st and 2nd sessions of nanohyperthermia) at a dose of $1.5 \mathrm{mg} / \mathrm{kg}$ b.w. Ordinate-tumor volume, $\mathrm{cm}^{3}$, abscise-time of observation from the first treatment, days. Data are presented as the mean \pm s.e.m.

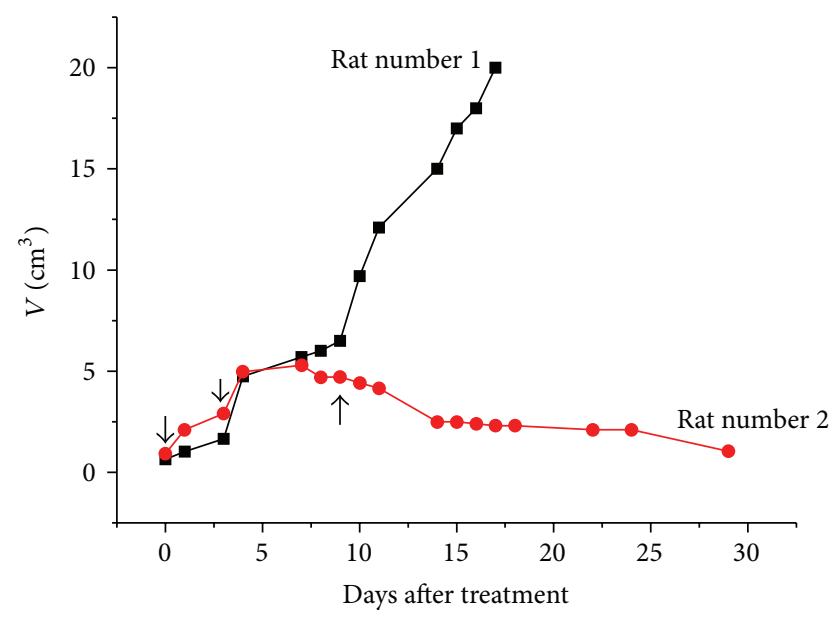

FIGURE 9: Rat number 2 (07.05.12) with Growth of Guerin carcinoma and non-treated control rat number 1 (07.05.12). Growth of Guerin carcinoma after combined treatment by MF with AMF supplemented with cisplatinum. a-growth of nontreated tumor; - - growth of treated tumor. Treatments (nanohyperthermia) were indicated with arrows. Cisplatinum was administered on the 1st and 2nd sessions of nanohyperthermia) at a dose of $1.5 \mathrm{mg} / \mathrm{kg} \mathrm{b.w}$. Ordinate-tumor volume, $\mathrm{cm}^{3}$, abscise-time of observation from the first treatment, days.

was observed (Table 2). These data allow to characterize the chemomodifying effect of nanohyperthermia as chemosensitization and to present it by means of conventional index, thermal enhancement ratio (TER) that is equal to 2.0 in this case. Moreover, based on the obtained data, it was also determined that nanohyperthermia in combination with cisplatin has resulted in complete regression (CR) of Guerin carcinoma

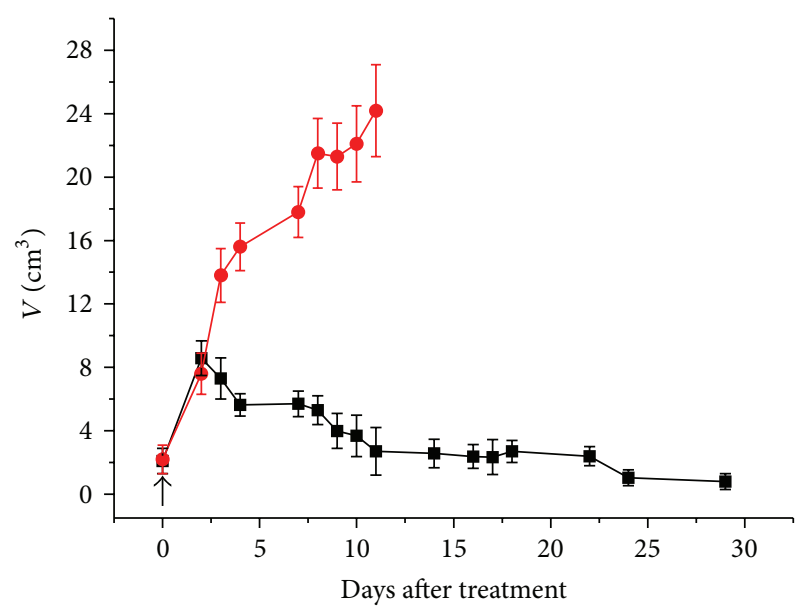

FIGURE 10: Growth of Walker-256 carcinosarcoma after combined treatment by MF with AMF supplemented with cisplatinum. Treatment was single (it was indicated with arrow) at a dose of $1.5 \mathrm{mg} / \mathrm{kg}$ b.w. - - growth of treated tumor; - growth of nontreated tumor. Ordinate-tumor volume, $\mathrm{cm}^{3}$, abscise-time of observation from the first treatment, days. Data are presented as the mean \pm s.e.m.

TABLE 2: Results of nanothermochemotherapy of rat's solid tumors.

\begin{tabular}{lcc}
\hline Tumor & $\begin{array}{c}\text { Number of rats with } \\
\text { complete tumor } \\
\text { regression }(\%)\end{array}$ & $\begin{array}{c}\text { Number of } \\
\text { cured rats }(\%)^{*}\end{array}$ \\
\hline $\begin{array}{l}\text { Guerin carcinoma } \\
\text { Untreated control }(n=7)\end{array}$ & 0 & 0 \\
$\begin{array}{l}\text { MF + AMF + cisplatin } \\
(1.5 \mathrm{mg} / \mathrm{kg})(n=15)\end{array}$ & 75.0 & 75.0 \\
$\begin{array}{l}\text { cisplatin } \\
(1.5 \mathrm{mg} / \mathrm{kg})(n=11)\end{array}$ & 32 & 25 \\
$\begin{array}{l}\text { cisplatin } \\
(3.0 \mathrm{mg} / \mathrm{kg})(n=14)\end{array}$ & 51 & 45 \\
Walker-256 carcinosarcoma & & 0 \\
$\begin{array}{l}\text { Untreated control }(n=6) \\
\text { MF + AMF + cisplatin } \\
(1.5 \mathrm{mg} / \mathrm{kg})(n=8)\end{array}$ & 0 & 80.0 \\
cisplatin \\
$\begin{array}{l}(1.5 \mathrm{mg} / \mathrm{kg})(n=11) \\
\text { cisplatin } \\
(3.0 \mathrm{mg} / \mathrm{kg})(n=12)\end{array}$
\end{tabular}

${ }^{*}$ Rats with complete tumor regression and without tumor recurrence within 120 days after complete regression of tumor; $n$ : number of rats; MF: magnetic fluid, AMF: alternating magnetic field.

in $75 \%$ of cases and CR of Walker-256 carcinosarcoma was determined in the $80 \%$ of cases. Chemomodifying effect of hyperthermia induced by conventional technique is known long ago [26], but the novelty of our results is the receiving of this effect by means of nanohyperthermia induced with manganite perovskite magnetic fluid.

In Vivo Evaluation of Nanohyperthermia Effect on the Metastasis of Lewis Lung Carcinoma. MF was given into the tumor at a dose of $200 \mathrm{mg} / \mathrm{kg}$ followed by AMF during $15 \mathrm{~min}$ 
TABLE 3: Lewis lung carcinoma growth and metastasis value after treatment of primary tumor with MF combined with AMF.

\begin{tabular}{|c|c|c|}
\hline Animal groups & $\begin{array}{l}\text { Change in the volume of primary tumor (on the 15th } \\
\text { day after the treatment) }\end{array}$ & $\begin{array}{l}\text { Number of metastases in lungs per } \\
\text { mice }\end{array}$ \\
\hline $\begin{array}{l}\text { Nontreated tumor-bearing } \\
\text { mice, } n=20\end{array}$ & Increase by 20 -fold & $24 \pm 2.3$ \\
\hline $\begin{array}{l}\text { Nanohyperthermia of primary } \\
\text { tumor, } n=25\end{array}$ & $\begin{array}{l}\text { Increase by } 5 \text {-fold } \\
\text { (complete regression of primary tumor was determined } \\
\text { in } 57 \% \text { of mice. Tumors have regressed mostly through } \\
\text { necrosis and following rejection of tumor mass) }\end{array}$ & $\begin{array}{l}8 \pm 0.8 \\
\text { (lung metastases were not } \\
\text { determined in } 43 \% \text { of mice among } \\
\text { all mice which have been treated) }\end{array}$ \\
\hline
\end{tabular}

$n$ : number of mice.

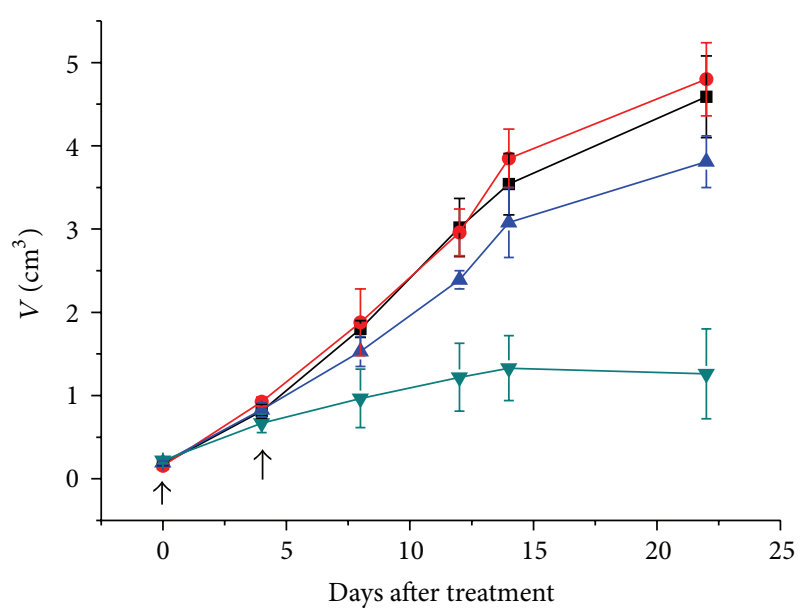

FIGURE 11: Lewis lung carcinoma growth after two combined treatments by MF with AMF (indicated with arrows) versus nontreated, treated with MF alone as well as AMF alone ( $\mathbf{-}$-non-treated, -

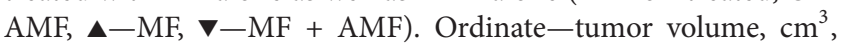
abscise - time of observation from the first treatment, days. Data are presented as the mean \pm s.e.m.

[27]. The treatment was performed twice with 3 days break. The following groups were used: (1) untreated tumor-bearing mice; (2) mice with tumors that were treated twice by AMF alone; (3) mice with tumors that were injected by MF alone once at the day of the 1st treatment; (4) mice with tumors that were injected by MF once at the day of the 1st treatment followed by AMF. MF dose, AMF regime, and treatment days in groups 2,3 , and 4 were the same. The volume of primary tumor in untreated group of animals was increased by 20 fold at the 22nd day of observation after the 1st treatment, in average, whereas the volume of the primary tumor in the 4th group (MF + AMF) was increased by 5 -fold, in average (Figure 11). At the same time in this group, complete regression of tumor was observed in $57 \%$ of mice. The evaluation of nanohyperthermia influence on the metastasis has determined that the average number of metastases in lung was $24 \pm 2.3$ metastases per mice at the 22nd-24th days of observation after 1st treatment in the untreated animals. The number of metastases in mice in the 2 nd and the 3 rd groups was $16 \pm 1.3$ and $11 \pm 1.2$ metastases per mice, respectively (Table 3). The number of metastases in lung in the 4 th group was $8.0 \pm 0.8$ metastases per mice. Moreover, the metastases were absent in $43 \%$ of mice in this group. Obtained results have distinctly shown the absence of stimulation of metastasis under nanohyperthermia treatment.

\section{Discussion}

Pollert et al. [15] have synthesized $\mathrm{La}_{1-x} \mathrm{Sr}_{x} \mathrm{MnO}_{3}$ nanoparticles by sol-gel technology. Single-phase perovskite structure was formed after heating of precursor at the temperature $650-900^{\circ} \mathrm{C}$ in air for $3 \mathrm{~h}$. When precursor was heated in such manner the size of particles was increased from 20 to $120 \mathrm{~nm}$, and essential interactions between particles were observed (Figure 12(a)). Therefore, further Pollert et al. [15] have applied the grinding with the aim to separate particles but in this case it was not allowed to obtain the single-size particles. We have also used the sol-gel method but it was improved [16]. It has given the possibility to decrease the size of $\mathrm{La}_{1-x} \mathrm{Sr}_{x} \mathrm{MnO}_{3}$ nanoparticles and markedly reduce the interaction between them (Figure 12(b)). It is important to note that SLP of MF on the basis of $\mathrm{La}_{1-x} \mathrm{Sr}_{x} \mathrm{MnO}_{3}$ nanoparticles was obtained in the range of $2000-2200 \mathrm{~W} / \mathrm{g}$ [28].

In model experiments, it was determined that the temperature of MF on the basis of lanthanum-strontium manganite under AMF $(300 \mathrm{kHz}, 7.7 \mathrm{kA} / \mathrm{m})$ was increased up to $72-75^{\circ} \mathrm{C}$ within the first $10 \mathrm{~min}$ of AMF action. It was also shown that the specimens of MF synthesized in different time during our study were heated practically up to the same level range of the increase of temperature $\left(0.4-0.7^{\circ} \mathrm{C}, P>0.05\right)$. It has to be noted that the distinctions in the effect of different specimens of MF were not also detected in vivo experiments aimed both to evaluate the heating of muscle or tumors and antitumor effect of nanohyperthermia. This observation allows to emphasize the stabile ability of synthesized MF to be heated under AMF.

Experiments in vivo with rats have allowed to determine that temperature in tumor was more higher than that in muscle after administration of MF followed by AMF within the same time of the heating. It is very relevant that in vivo experiments with transplanted tumors of rats, in particular Guerin carcinoma, have determined that administration of MF into the tumor followed by AMF within 20-30 min has resulted in the CR of tumor in the $35 \%$ of rats. Administration of MF alone into the tumor as well as action of AMF alone has not resulted in the delay of tumor growth. It has to be mentioned that the inhibition of tumor growth of transplanted tumors, in particular Guerin carcinoma due 

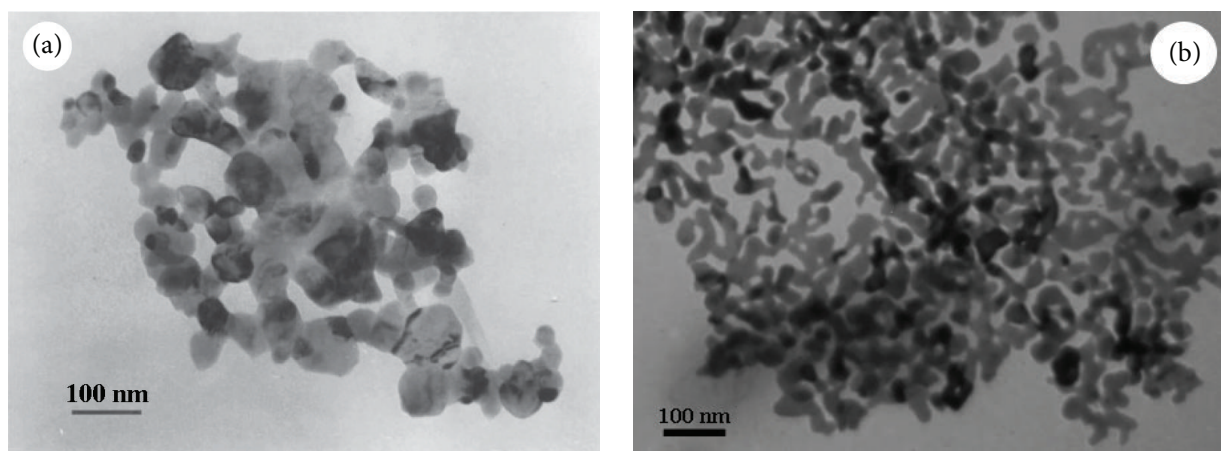

FIGURE 12: $\mathrm{La}_{1-x} \mathrm{Sr}_{x} \mathrm{MnO}_{3}$ nanoparticles that have been synthesized by sol-gel method. (a) Nanoparticles synthesized by [15]; (b) nanoparticles synthesized by authors of this study [16].

to nanohyperthermia, was more significant than that after microwave hyperthermia (2450 $\mathrm{MHz}$ or $434 \mathrm{MHz}$ ) applied as a single mean [29]. The chemomodifying effect of nanohyperthermia was also determined, in particular, for cisplatin that was assessed by thermal enhancement ratio 2.0.

In vivo experiments with Lewis lung carcinoma have shown that administration of MF into the tumor under AMF within $15 \mathrm{~min}$ has resulted in the inhibition of primary tumor growth $(P<0.05)$ with CR of tumor in $57 \%$ of mice through necrosis. It is relevant that nanohyperthermia has not only caused the stimulation of metastasis into the lung, but on the contrary it has resulted in the inhibition of metastasis. The absence of metastases in the lung was recognized in $43 \%$ of animals and the decrease of metastases number by 3 -fold in mice treated with nanohyperthermia in comparison with untreated animals.

\section{Conclusions}

The increase of temperature was shown in vivo in transplanted rodent tumors after intratumoral administration of MF based on manganite perovskite nanoparticles followed by $\mathrm{AMF}$ up to $47^{\circ} \mathrm{C}$ at the 30 th $\min$ of the heating. Administration of MF supplemented with AMF has resulted in the complete regression of tumor in 35\% of rats in comparison with untreated ones. The chemomodifying effect of nanohyperthermia, in particular for cisplatin, was also shown. It was observed that nanohyperthermia induced by manganite perovskite MF under AMF has resulted in the inhibition of Lewis lung carcinoma metastasis: the absence of metastases in $43 \%$ of mice. Obtained results allow suggesting that the preclinical evaluation of synthesized MF based on nanoparticles of lanthanum-strontium manganite perovskite is promising. At the same time special investigation to optimize synthesis of MF to receive optimum characteristic of nanoparticles, in particular their size, coating, and organic matrix, is necessary.

\section{Conflict of Interests}

The authors report no conflict of interests. The authors alone are responsible for the content and writing of the paper.

\section{Acknowledgments}

This research was supported by the National Academy of Sciences of Ukraine (Program "Basic problems of nanostructure systems, nanomaterials, nanotechnologies," Grant no. 111/H1, and Program of Fundamental Studies "Fine Chemicals").

\section{References}

[1] J. van der Zee, Z. Vujaskovic, M. Kondo, and T. Sugahara, "The Kadota Fund International Forum 2004-clinical group consensus," International Journal of Hyperthermia, vol. 24, no. 2, pp. 111-122, 2008.

[2] R. D. Issels, L. H. Lindner, J. Verweij et al., "Neo-adjuvant chemotherapy alone or with regional hyperthermia for localised high-risk soft-tissue sarcoma: a randomised phase 3 multicentre study," The Lancet Oncology, vol. 11, no. 6, pp. 561-570, 2010.

[3] P. Kaur, M. D. Hurwitz, S. Krishnan, and A. Asea, "Combined hyperthermia and radiotherapy for the treatment of cancer," Cancers, vol. 3, no. 4, pp. 3799-3823, 2011.

[4] A. Jordan, P. Wust, H. Fähling, W. John, A. Hinz, and R. Felix, "Inductive heating of ferrimagnetic particles and magnetic fluids: physical evaluation of their potential for hyperthermia," International Journal of Hyperthermia, vol. 9, no. 1, pp. 51-68, 1993.

[5] B. Thiesen and A. Jordan, "Clinical applications of magnetic nanoparticles for hyperthermia," International Journal of Hyperthermia, vol. 24, no. 6, pp. 467-474, 2008.

[6] G. Bellizzi and O. M. Bucci, "On the optimal choice of the exposure conditions and the nanoparticle features in magnetic nanoparticle hyperthermia," International Journal of Hyperthermia, vol. 26, no. 4, pp. 389-403, 2010.

[7] W. C. Zamboni, V. Torchilin, A. K. Patri et al., "Best practices in cancer nanotechnology: perspective from NCI nanotechnology alliance," Clinical Cancer Research, vol. 18, no. 12, pp. 3229-3241, 2012.

[8] I. Hilger, R. Hiergeist, R. Hergt, K. Winnefeld, H. Schubert, and W. A. Kaiser, "Thermal ablation of tumors using magnetic nanoparticles: an in vivo feasibility study," Investigative Radiology, vol. 37, no. 10, pp. 580-586, 2002.

[9] S. Laurent, S. Dutz, U. O. Häfeli, and M. Mahmoudi, "Magnetic fluid hyperthermia: focus on superparamagnetic iron oxide nanoparticles," Advances in Colloid and Interface Science, vol. 166, no. 1-2, pp. 8-23, 2011. 
[10] A. P. Khandhar, R. M. Ferguson, J. A. Simon, and K. M. Krishnan, "Enhancing cancer therapeutics using size-optimized magnetic fluid hyperthermia," Journal of Applied Physics, vol. 111, no. 7, Article ID 07B306, 2012.

[11] K. Maier-Hauff, F. Ulrich, D. Nestler et al., "Efficacy and safety of intratumoral thermotherapy using magnetic ironoxide nanoparticles combined with external beam radiotherapy on patients with recurrent glioblastoma multiforme," Journal of Neuro-Oncology, vol. 103, no. 2, pp. 317-324, 2011.

[12] M. Johannsen, B. Thiesen, P. Wust, and A. Jordan, "Magnetic nanoparticle hyperthermia for prostate cancer," International Journal of Hyperthermia, vol. 26, no. 8, pp. 790-795, 2010.

[13] Q. Zhao, L. Wang, R. Cheng et al., "Magnetic nanoparticlebased hyperthermia for head \& neck cancer in mouse models," Theranostics, vol. 2, no. 1, pp. 113-121, 2012.

[14] K. Hayashi, M. Nakamura, W. Sakamoto et al., "Superparamagnetic nanoparticle clusters for cancer theranostics combining magnetic resonance imaging and hyperthermia treatment," Theranostics, vol. 3, no. 6, pp. 366-376, 2013.

[15] E. Pollert, O. Kaman, P. Veverka et al., "Core-shell $\mathrm{La}_{1-x} \mathrm{Sr}_{x}$ $\mathrm{MnO}_{3}$ nanoparticles as colloidal mediators for magnetic fluid hyperthermia," Philosophical Transactions of the Royal Society A, vol. 368, no. 1927, pp. 4389-4405, 2010.

[16] S. O. Solopan, O. I. V’Yunov, A. G. Belous, T. I. Polek, and A. I. Tovstolytkin, "Effect of nanoparticles agglomeration on electrical properties of $\mathrm{La}_{1-x} \mathrm{~A}_{x} \mathrm{MnO}_{3}(\mathrm{~A}=\mathrm{Sr}, \mathrm{Ba})$ nanopowder and ceramic solid solutions," Solid State Sciences, vol. 14, no. 4, pp. 501-505, 2012.

[17] S. Vasseur, E. Duguet, J. Portier et al., "Lanthanum manganese perovskite nanoparticles as possible in vivo mediators for magnetic hyperthermia," Journal of Magnetism and Magnetic Materials, vol. 302, no. 2, pp. 315-320, 2006.

[18] E. Pollert, K. Knížek, M. Maryško, P. Kašpar, S. Vasseur, and E. Duguet, "New $\mathrm{T}_{c}$-tuned magnetic nanoparticles for selfcontrolled hyperthermia," Journal of Magnetism and Magnetic Materials, vol. 316, no. 2, pp. 122-125, 2007.

[19] A. A. Kuznetsov, O. A. Shlyakhtin, N. A. Brusentsov, and O. A. Kuznetsov, "Smart' mediators for self-controlled inductive heating," European Cells and Materials, vol. 3, supplement 2, pp. 75-77, 2002.

[20] V. Uskoković, A. Košak, and M. Drofenik, "Preparation of silica-coated lanthanum-strontium manganite particles with designable curie point, for application in hyperthermia treatments," International Journal of Applied Ceramic Technology, vol. 3, no. 2, pp. 134-143, 2006.

[21] E. Natividad, M. Castro, G. Goglio et al., "New insights into the heating mechanisms and self-regulating abilities of manganite perovskite nanoparticles suitable for magnetic fluid hyperthermia," Nanoscale, vol. 4, no. 13, pp. 3954-3962, 2012.

[22] S. Sakka, Ed., Handbook of Sol-Gel Science and Technology: Processing, Characterization and Application, Kluwer Academic Publishers, New York, NY, USA, 2005.

[23] A. G. Belous, O. I. V’yunov, E. V. Pashkova, O. Z. Yanchevskii, A. I. Tovstolytkin, and A. M. Pogorelyi, "Effects of chemical composition and sintering temperature on the structure of $\mathrm{La}_{1-x} \mathrm{Sr}_{x} \mathrm{MnO}_{3 \pm \gamma}$ solid solutions," Inorganic Materials, vol. 39, no. 2, pp. 161-170, 2003.

[24] S. Solopan, A. Belous, A. Yelenich et al., "Nanohyperthermia of malignant tumors. I. Lanthanum-strontium manganite magnetic fluid as potential inducer of tumor hyperthermia," Experimental Oncology, vol. 33, no. 3, pp. 130-135, 2011.
[25] L. Bubnovskaya, A. Belous, A. Solopan et al., "Nanohyperthermia of malignant tumors. II. In vivo tumor heating with manganese perovskite nanoparticles," Experimental Oncology, vol. 34, no. 4, pp. 336-339, 2012.

[26] R. D. Issels, "Hyperthermia adds to chemotherapy," European Journal of Cancer, vol. 44, no. 17, pp. 2546-2554, 2008.

[27] A. Belous, S. Solopan, A. Yelenich, L. Bubnovskaya, S. Osinsky, and L. Bovkun, "Synthesis and properties of ferromagnetic nanoparticles for potential biomedical application," in Proceedings of the 34th IEEE International Scientific Conference on "Electronics and Nanotechnology" (ELNANO '14), Conference Proceedings, pp. 245-249, Kyiv, Ukraine, April 2014.

[28] A. Belous, S. Solopan, A. Yelenich, L. Bubnovskaya, and S. Osinsky, "Nanoparticles of ferromagnetic materials and possibilities of their application in the hyperthermia of malignant tumors," in Proceedings of the IEEE 33rd International Scientific Conference Electronics and Nanotechnology (ELNANO '13), pp. 280-284, Kyiv, Ukraine, April 2013.

[29] S. Osinsky, L. Bubnovskaja, and A. Gusev, "Procedures for improving therapeutic gain," Advances in Experimental Medicine and Biology, vol. 267, pp. 251-270, 1990. 

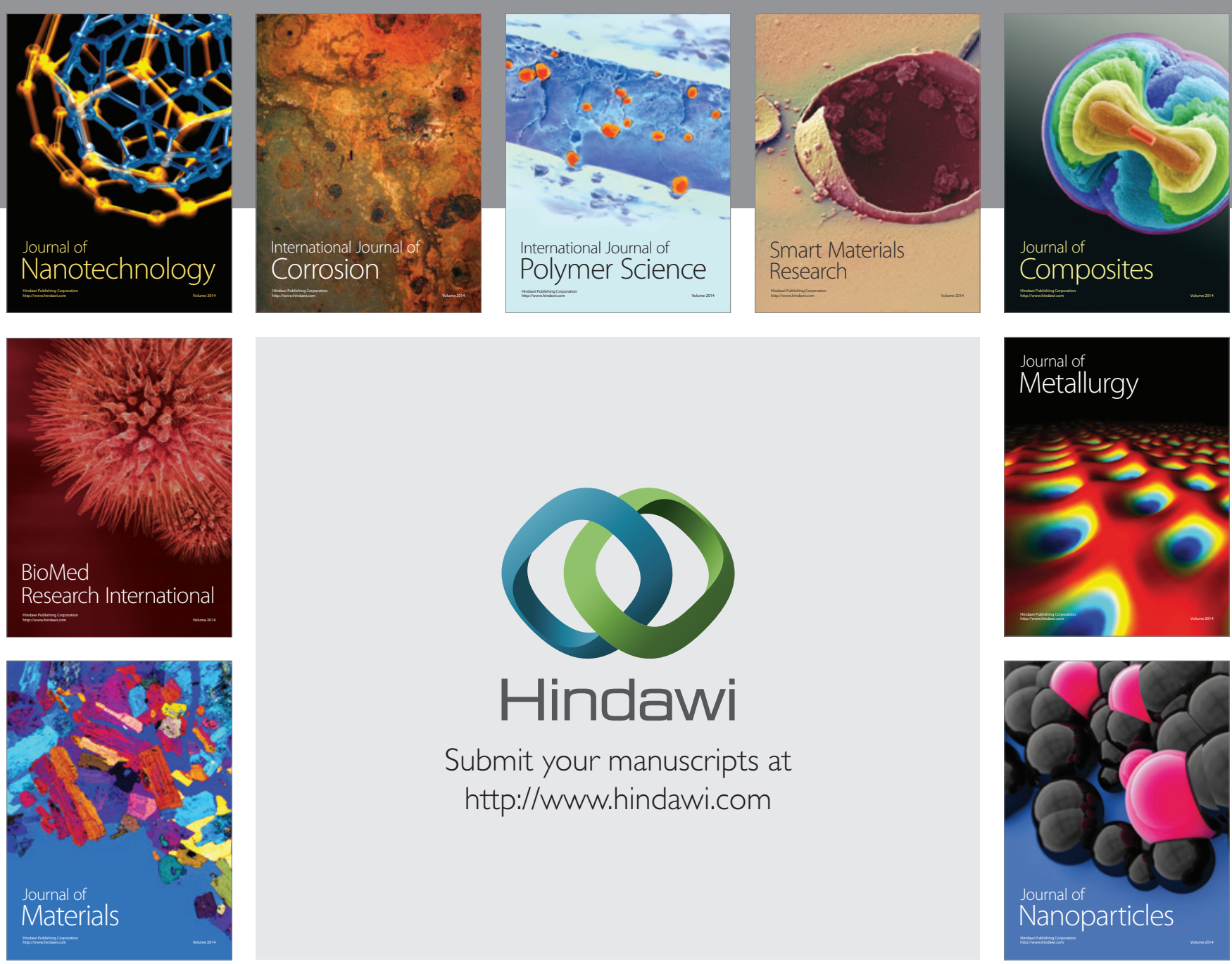

Submit your manuscripts at http://www.hindawi.com
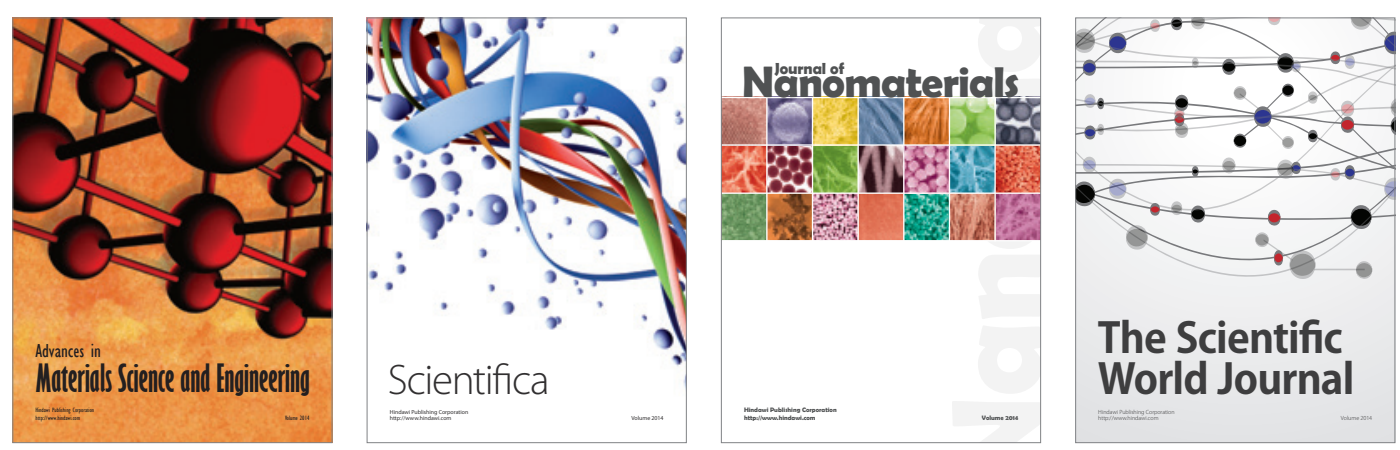

\section{The Scientific World Journal}
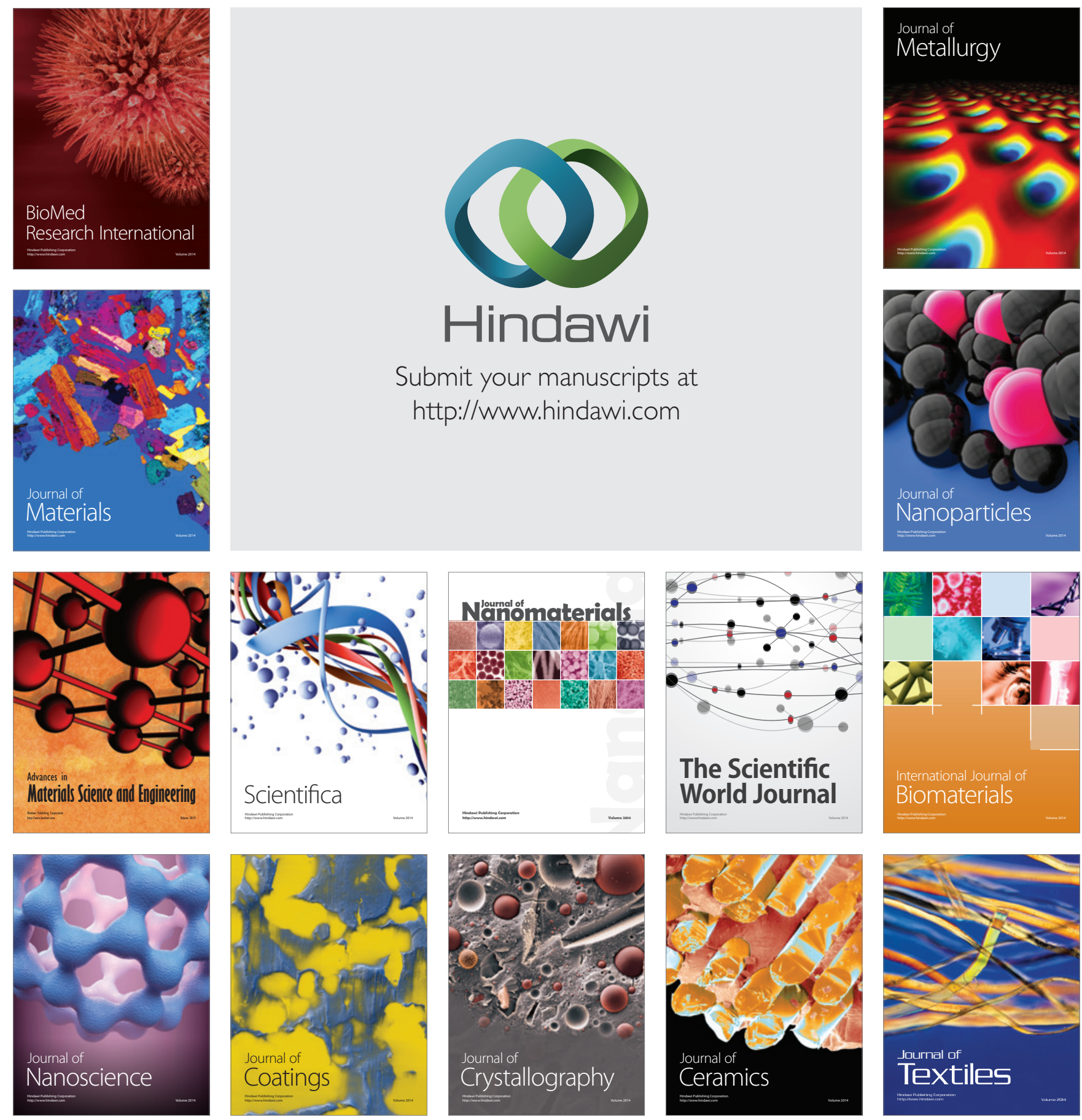